\title{
Non-invasive diagnostics of the maxillary and frontal sinuses based on diode laser gas spectroscopy*
}

\author{
Märta Lewander', Sven Lindberg², Tomas Svensson', Roger Siemund³, \\ Katarina Svanberg ${ }^{4}$ and Sune Svanberg 1 \\ Division of Atomic Physics, Department of Physics, Lund University, Lund, Sweden \\ Department of Oto-Rhino-Laryngology, University Hospital, Lund University, Lund, Sweden \\ Department of Diagnostic Radiology, University Hospital, Lund University, Lund, Sweden \\ Department of Oncology, University Hospital, Lund University, Lund, Sweden
}

Rhinology 50: 26-32, 2012 DOI: $10.4193 /$ Rhino 10.231

*Received for publication:

October 14, 2010;

accepted: October 11, 2011

\section{Summary}

Problem: Suspected, but objectively absent, rhinosinusitis constitutes a major cause of visits to the doctor, high health care costs, and the over-prescription of antibiotics, contributing to the serious problem of resistant bacteria. This situation is largely due to a lack of reliable and widely applicable diagnostic methods.

Method: A novel method for the diagnosis of rhinosinusitis based on non-intrusive diode laser gas spectroscopy is presented. The technique is based on light absorption by free gas (oxygen and water vapour) inside the sinuses, and has the potential to be a complementary diagnostic tool in primary health care. The method was evaluated on 40 patients with suspected sinus problems, referred to the diagnostic radiology clinic for low-dose computed tomography (CT), which was used as the reference technique.

Main results: The data obtained with the new laser-based method correlated well with the grading of opacification and ventilation using CT. The sensitivity and specificity were estimated to be $93 \%$ and $61 \%$, respectively, for the maxillary sinuses, and $94 \%$ and $86 \%$, respectively, for the frontal sinuses. Good reproducibility was shown.

Principal conclusion: The laser-based technique presents real-time clinical data that correlate well to CT findings, while being non-intrusive and avoiding the use of ionizing radiation.

Key words: paranasal sinus disease, diagnostic techniques and procedures, optical device, laser, absorption

\section{Introduction}

Rhinosinusitis, i.e. inflammation of the nose and paranasal sinuses due to e.g. bacterial, viral or allergic reaction, constitutes a major socio-economic and health problem. Costs include the consultation of a physician, tests and medical treatment. In 2002, over one fifth of the prescriptions for antibiotics in the USA were for the treatment of rhinosinusitis. Most diagnoses of rhinosinusitis, approximately $87 \%$, are performed in primary health care clinics and are based on symptoms and clinical signs ${ }^{(1-3)}$.
The definition of rhinosinusitis is symptom-based: the major factors being facial pain, facial fullness/congestion, nasal obstruction/blockage, purulence in the nasal cavity, and discharge/purulence/discoloured postnasal drainage together with fever ${ }^{(4,5)}$. In 2007, the European Position Paper on Rhinosinusitis ${ }^{(6)}$ expanded the recommendations for the diagnosis of this complaint to include objective signs, such as mucosal obstruction, revealed by endoscopy or computed tomography (CT). It has been found that when objective measurements are included in the diagnostic process, a large proportion (approximately $73 \%$ ) of rhinosinusitis patients diagnosed as having 
rhinosinusitis according to the symptoms mentioned above, showed no evidence of the disease according to $\mathrm{CT}$ and/or endoscopic evaluation ${ }^{(7)}$. This group of patients thus does not require treatment with antibiotics, a fact that is important in restricting the use of antibiotics.

The cost of chronic rhinosinusitis to society is high due to the large number of outpatient visits and the medication prescribed ${ }^{(8)}$. The major contributors to the high outpatient cost are CT and nasal endoscopy. CT is especially costly, and considerable savings could be made if this could be replaced by an inexpensive non-invasive method for the diagnosis of rhinosinusitis. We present a potential diagnostic method, and the instrumentation required, that can be used by both ENT specialists and physicians in primary health care, which allows easy, non-invasive, repeated measurements. This newly developed technique provides information on the gas volume and composition of the gas in the maxillary and frontal sinuses. The method is based on a laser spectroscopic technique called GASMAS (GAs in Scattering Media Absorption Spectroscopy) ${ }^{(9)}$, which probes the free gas inside solids and liquids. GASMAS has already shown promising results in volunteers for both the frontal and maxillary sinuses ${ }^{(10,11)}$. The present paper presents the results from the first clinical trial carried out to study the diagnostic accuracy of GASMAS by comparing the findings to those from CT scans.

\section{Method}

\section{Participants}

The inclusion criterion for the study population was referral to the Lund University Hospital for low-dose CT due to suspected sinus disease. The patients received information on the clinical trial in the CT examination referral letter. Forty patients who gave their written consent were examined with the index test, i.e. the developed laser-based technique (GASMAS), directly after undergoing the $\mathrm{CT}$ scan. Both examinations were performed at the Diagnostic Radiology Clinic at the Lund University Hospital. No treatment was administered between the tests. The study was approved by the Regional Ethics Committee in Southern Sweden (No. 210-2007).

\section{Reference standard - Computed tomography}

The diagnostic accuracy of the laser-based technique GASMAS was evaluated against CT as a reference standard. CT was chosen as the reference technique because it provides objective confirmation of sinus disease.

The CT examinations were performed using a Philips Brilliance 64-slice scanner (Philips Healthcare, Best, the Netherlands) with the patient in the supine position. The acquisition parameters were: spiral mode, $80 \mathrm{kVp}, \mathrm{CTDI}_{\text {vol }} 0.7 \mathrm{mGy}, 1 \mathrm{~mm}$ slice thickness reconstructed with $50 \%$ overlap. From these primary slices, multiplanar reformations with $2 \mathrm{~mm}$ coronal and axial slices including the maxillary and frontal sinuses were reconstructed.

\section{Index test - Laser-based technique}

The examinations with the laser-based technique GASMAS were performed with an instrument ${ }^{(12)}$ developed at the Division of Atomic Physics at Lund University, depicted in Figure 1. The instrument measures the amount of free gas, oxygen $\left(\mathrm{O}_{2}\right)$, and water vapour $\left(\mathrm{H}_{2} \mathrm{O}\right)$, inside the sinus cavity, by measuring light absorption. The absorption by $\mathrm{H}_{2} \mathrm{O}$ is closely related to the volume of the gas probed, due to humidity saturation. The ratio of the absorption by $\mathrm{O}_{2}$ and $\mathrm{H}_{2} \mathrm{O}$ provides a measure of the $\mathrm{O}_{2}$ concentration inside the sinus. Both the absorption by $\mathrm{H}_{2} \mathrm{O}$ and the $\mathrm{O}_{2} / \mathrm{H}_{2} \mathrm{O}$ absorption ratio were analysed.

A detailed technical description of the instrument and data processing has been presented previously ${ }^{(12)}$. The instrument interfaces with the patient through two probes: a fibre probe (10 cm long, $1 \mathrm{~cm}$ in diameter), and a detector probe (a largearea photodiode, measuring $18 \times 18 \mathrm{~mm}^{2}$ ), which are held against the patient's face. The fibre probe transmits light (total energy of about $1.5 \mathrm{~mW}$ ) from two diode lasers, emitting at $760 \mathrm{~nm}$ and $935 \mathrm{~nm}$ for the detection of $\mathrm{O}_{2}$ and $\mathrm{H}_{2} \mathrm{O}$, respectively. Laser drivers, an optical breadboard and a computer with a data acquisition card (DAQ) are assembled on a rolling cart. A long optical fibre to the light transducer (fibre probe) and a long signal cable to the light detector (detector probe) enable easy access to the sinuses of the patient during examination.

The index tests were performed on the maxillary and frontal sinuses on both sides of the patient. The measurement geometries are depicted in Figure 1. For examination of the maxillary sinus, the fibre probe is placed inside the mouth on the palate, on the right or left side pointing towards the sinus to be examined. The detector probe is placed on the cheekbone anteriorly under the eye, in direct contact with the skin. For frontal sinus examinations the fibre probe is placed at the location of the frontal bone directed towards the sinus. The detector is positioned on the frontal bone above the eyebrow. Each sinus was examined four times, the probes being repositioned between measurements. A measuring time of 20 seconds, corresponding to 200 averages of the signal, was used. During measurements the lights in the room were turned off, and the patient wore laser-light protective goggles.

Data evaluation

The diagnostic accuracy of the laser-based technique was investigated by comparing the results obtained from CT scans (i.e. the reference standard). The status of the examined 
sinuses was determined from the CT scans by a senior radiologist, using a previously established classification scheme for sinuses ${ }^{(13)}$. The classification includes grading of aeration, ventilation and anatomic variants of the sinus. The grade describes the opacification of the sinus: 0 - no abnormality, 1 - partial opacification, and 2 - total opacification. Obstruction of the ostiomeatal complex (OMC) classifies the ventilation as: 0 - not obstructed, or 2 - obstructed. The anatomic variants are classified as 0 - normal and $1-$ absent sinus.

Two parameters obtained with the index test measurement: the absorption by $\mathrm{H}_{2} \mathrm{O}$ and the ratio of the absorption by $\mathrm{O}_{2}$ and $\mathrm{H}_{2} \mathrm{O}$, were compared with the $\mathrm{CT}$ findings. As stated above, the absorption by $\mathrm{H}_{2} \mathrm{O}$ is related to the gas volume probed, while the ratio of the absorption by $\mathrm{O}_{2}$ and $\mathrm{H}_{2} \mathrm{O}$ provides a measure of the oxygen content in the sinus. There should thus be a correlation between opacification determined by the $\mathrm{CT}$ scan evaluation and low $\mathrm{H}_{2} \mathrm{O}$ absorption determined by the index test. Impaired ventilation of the sinus according to $\mathrm{CT}$ evaluation should be seen as a low ratio between the $\mathrm{O}_{2}$ and $\mathrm{H}_{2} \mathrm{O}$ absorption in the index test, due to a decrease in $\mathrm{O}_{2}$ concentration resulting from adsorption by the tissue ${ }^{(14)}$.

The results of the reference standard and the index test were obtained under blinded conditions. The investigators were blinded regarding the results of the CT scan during the index test (laser measurements) and during the subsequent data processing. Likewise, the radiologist analysing the CT scans was unaware of the results obtained with the laser-based method.

\section{Statistical methods}

The sensitivity and specificity of the index test were estimated by applying threshold values of the test parameters, calculated from the healthy patients. The examined sinuses were divided into two subgroups: healthy sinuses and sinuses with pathology. The results obtained from the healthy sinuses with the index test, i.e. classified as showing no opacification or obstruction of the $\mathrm{OMC}$ in the $\mathrm{CT}$ evaluation, were analysed assuming a normal distribution. Thresholds of the index test parameters, $\mathrm{H}_{2} \mathrm{O}$ absorption and ratio of $\mathrm{O}_{2}$ and $\mathrm{H}_{2} \mathrm{O}$ absorption, were determined from the $95 \%$ confidence intervals. The sensitivity and specificity were estimated using the thresholds obtained for the frontal and maxillary sinus, individually.

The reproducibility of the index test was evaluated from the four consecutive individual gas absorption measurements. The deviation between the index test parameters obtained from the same sinus was calculated and used for reproducibility analysis.
Table 1. Sinus status of the study population, according to the reference standard evaluation (CT scans).

\begin{tabular}{|c|c|c|c|c|c|c|c|}
\hline \multicolumn{4}{|c|}{$\begin{array}{l}\text { Maxillary sinus } \\
\qquad \mathbf{8 0} \text { sinuses }\end{array}$} & \multicolumn{4}{|c|}{ Frontal sinus } \\
\hline \multicolumn{4}{|c|}{ OMC } & & & \multicolumn{2}{|c|}{ OMC } \\
\hline \multirow{4}{*}{$\begin{array}{l}\frac{0}{0} \\
\frac{\pi}{0}\end{array}$} & & 0 & 2 & \multirow{4}{*}{$\begin{array}{l}\frac{0}{0} \\
\frac{\pi}{0}\end{array}$} & & 0 & 2 \\
\hline & 0 & 60 & 2 & & 0 & 68 & 2 \\
\hline & 1 & 12 & 5 & & 1 & 2 & 1 \\
\hline & 2 & 0 & 1 & & 2 & 1 & 0 \\
\hline
\end{tabular}

Table 2. Overview of diagnostic accuracy.

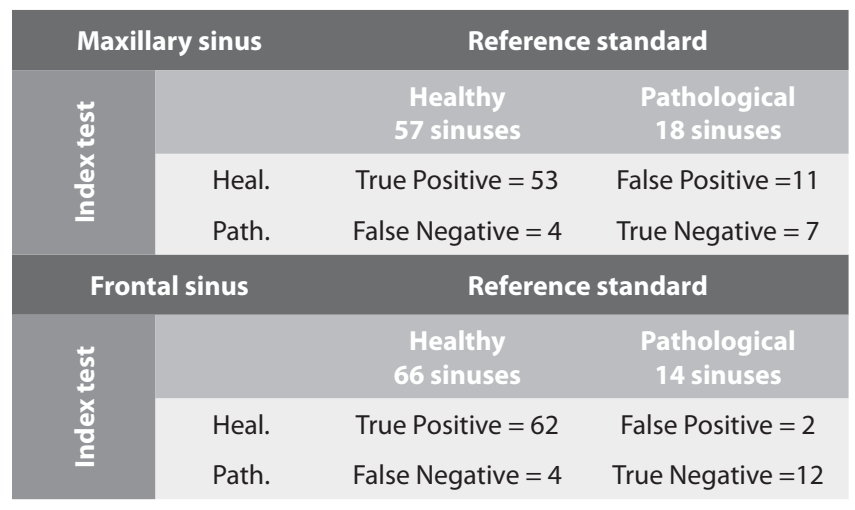

\section{Results}

In the present study, 40 patients underwent examinations with the reference standard and the index tests. The examinations took place between October 21, 2008 and February 29, 2009. The study population consisted of 10 men, aged $22-83$ years ( $57 \pm 16$ years), and 30 women aged $30-84$ years $(54 \pm$ 14 years). The patients did not report any discomfort during the laser-based examination, which lasted approximately 15 minutes.

The distribution of the sinus conditions of the study population shows that the majority of the sinuses were classified as healthy according to the results of the reference standard (Table 1). Only $25 \%$ of the maxillary sinuses examined were opacified (Grade 1 or 2) or showed obstructed ventilation (OMC 2). The corresponding proportion for the frontal sinuses was $12 \%$, including $7.5 \%$ with an absent sinus.

Data from 25 measurements using the index test are missing due to technical problems or limited light transmission 


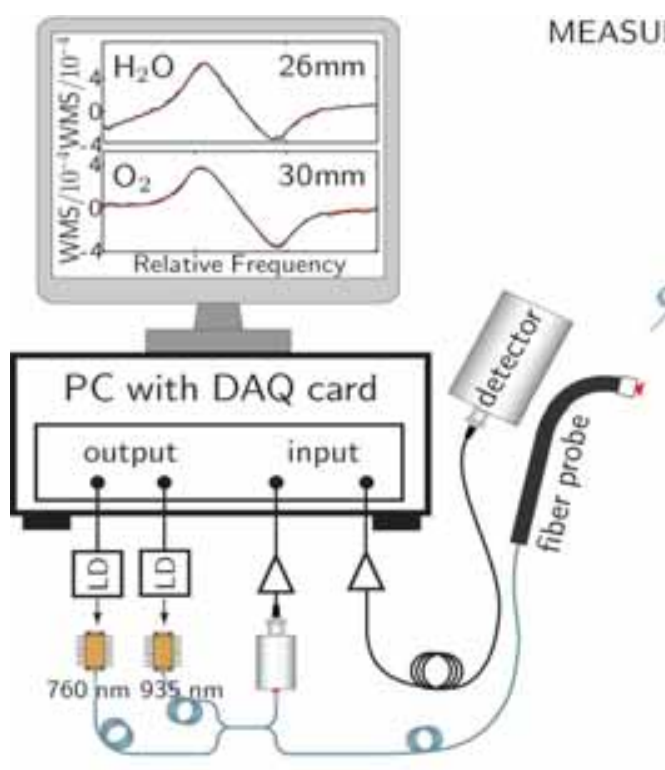

MEASUREMENT GEOMETRIES
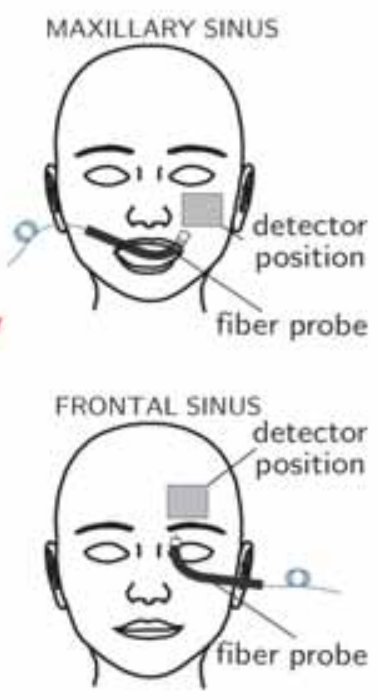

Figure 1. The set-up of the laser-based method showing the measurement geometry of frontal and maxillary sinuses. Absorption signals from a frontal sinus are shown on the monitor. A modulation technique was used so the gas absorption signal has the shape of the derivative of the light absorption. through the examined sinus. The missing data correspond to $3.9 \%$ of the total 640 index test measurements performed (4 sinuses in each patient, and 4 measurements on each sinus). Technical problems, such as incorrectly saved files and saturated amplification, resulted in the loss of 9 measurements. Four of the maxillary sinuses examined ( 16 measurements) could not be evaluated due to the low level of laser light detected. Of the 25 missing measurements, five are a single measurement among the four consecutive measurements performed on a particular sinus. The 3 values obtained for these sinuses were used for the evaluation of the diagnostic accuracy of the method. The 5 sinuses for which no index test data were available were not included in the comparison of the reference standard and index test. The CT evaluation of these sinuses showed four healthy sinuses (Grade 0 and OMC 0 ), and one partially patent sinus (Grade 1 and OMC 0).

The results of the index test parameters, absorption by $\mathrm{H}_{2} \mathrm{O}$ and the ratio of $\mathrm{O}_{2}$ and $\mathrm{H}_{2} \mathrm{O}$ absorption are shown in Figure 2, in relation to their classification from the $\mathrm{CT}$ images. Sinuses with $\mathrm{H}_{2} \mathrm{O}$ absorption below the detection limit of the index test instrument, i.e. $2 \mathrm{~mm}^{(12)}$, were excluded from the evaluation of the ratio. It can be seen that the sinuses with no gas-containing cavity, Grade 2 or absent sinuses, exhibit no $\mathrm{H}_{2} \mathrm{O}$ absorption. The maxillary sinuses with a partially gas-filled cavity (Grade 1) show a lower $\mathrm{H}_{2} \mathrm{O}$ absorption than aerated sinuses (Grade 0). This clear differentiation between Grades 1 and 0 was not seen in the data obtained from the frontal sinuses. Gas-filled, but unventilated maxillary and frontal sinuses
(Grade 0 and $\mathrm{OMC} 2$ ) show no anomaly in $\mathrm{H}_{2} \mathrm{O}$ absorption, but 3 out of 5 exhibited a reduced oxygen concentration. Low $\mathrm{H}_{2} \mathrm{O}$ absorption in the index test identifies obstructed and absent sinuses well, and a low $\mathrm{O}_{2} / \mathrm{H}_{2} \mathrm{O}$ absorption ratio identifies unventilated sinuses.

The $\mathrm{H}_{2} \mathrm{O}$ absorption (which is a measure of the volume of gas) and the $\mathrm{O}_{2} / \mathrm{H}_{2} \mathrm{O}$ absorption ratio (which provides a measure of the oxygen concentration) provide complementary information. The clinical applicability of the index test should thus be evaluated using both these parameters together. Presenting the measured absorption of $\mathrm{O}_{2}$ and $\mathrm{H}_{2} \mathrm{O}$ of a particular sinus together, illustrates a way to expose both index test parameters with retained sinus identity. Figure 3 shows the index test data obtained in this way demonstrating the suitability of this approach. The sinuses classified as healthy (Grade 0 and OMC 0) exhibit strongly positively correlated values of $\mathrm{O}_{2}$ and $\mathrm{H}_{2} \mathrm{O}$ absorption that lie around the line $y=x$. This indicates that the gas volumes of $\mathrm{O}_{2}$ and $\mathrm{H}_{2} \mathrm{O}$ probed were similar, and that the $\mathrm{O}_{2}$ concentration is similar to the ambient concentration. A clear deviation from the line $\mathrm{y}=\mathrm{x}$ indicates an abnormal oxygen concentration. Low values of $\mathrm{H}_{2} \mathrm{O}$ and $\mathrm{O}_{2}$ absorption, i.e. low gas volume, are located in the lower left corner of each plot. The data presented in Figure 3 provide information on the gas volume and oxygen concentration in a particular sinus, in contrast to the data presented in Figure 2.

The data and thresholds presented in Figure 3 yield a sensitivity and specificity of $93 \%$ and $61 \%$ for the maxillary sinuses, 

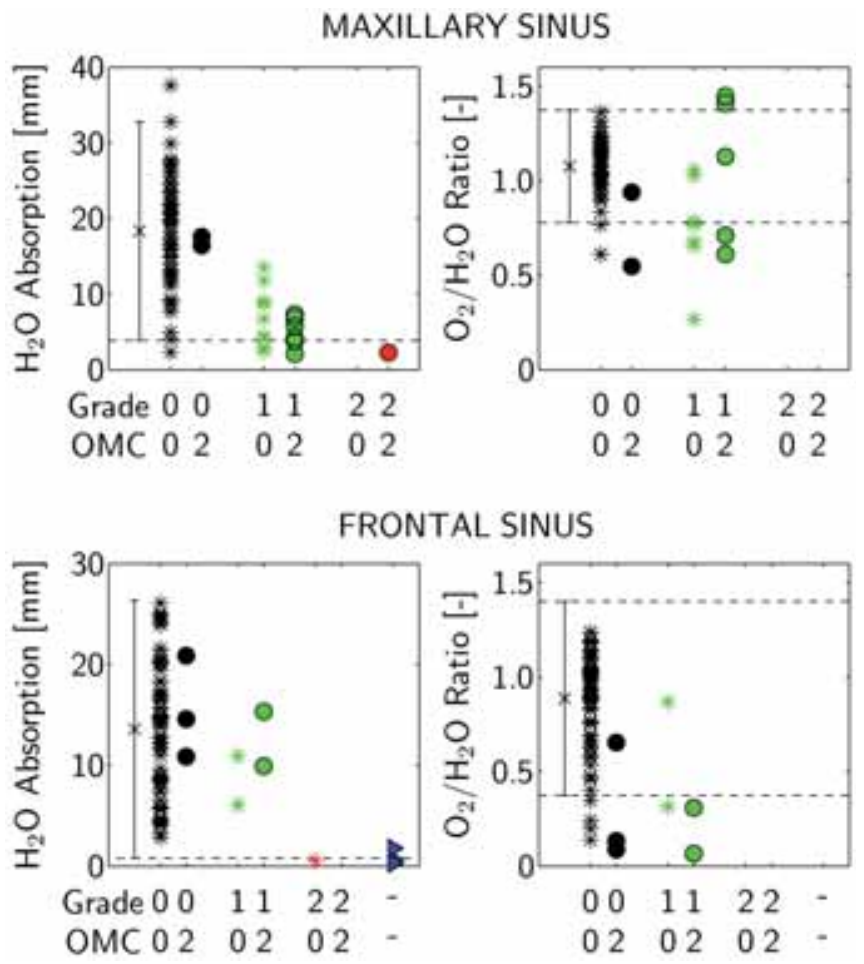

Figure 2. Index test parameters categorized according to the CT classification, for the maxillary sinuses (above) and the frontal sinuses (below). The mean values for sinuses with Grade 0 and OMC 0 are shown on the left in the graphs, together with the $95 \%$ confidence interval (dashed lines). Left: Absorption by $\mathrm{H}_{2} \mathrm{O}$. Right: Ratio of $\mathrm{O}_{2}$ and $\mathrm{H}_{2} \mathrm{O}$ absorption.

and $94 \%$ and $86 \%$ for the frontal sinuses (Table 2). Sinuses with any kind of pathological finding according to the reference standard classification (CT scans) are treated as one group. Both parameters of the index test, $\mathrm{H}_{2} \mathrm{O}$ absorption and $\mathrm{O}_{2} / \mathrm{H}_{2} \mathrm{O}$ absorption, were used to determine the diagnostic accuracy. The estimated sensitivity and specificity provide information about the possibility of distinguishing sinuses with pathological conditions from healthy sinuses (Grade 0 and OMC 0 ).

The index test showed good reproducibility. The variation between the four consecutive measurements on each sinus with the laser-based technique was small. For the maxillary sinus, the average deviation between the measurements on the same sinus was $2.0 \mathrm{~mm}$ for the $\mathrm{H}_{2} \mathrm{O}$ absorption and 0.09 for the $\mathrm{O}_{2} / \mathrm{H}_{2} \mathrm{O}$ ratio. The corresponding values for the frontal sinus were $1.2 \mathrm{~mm}$ and 0.09 .

\section{Discussion}

The results of this study show that there is good correlation between the reference standard (CT scans) and the index test (laser-based technique GASMAS). They also demonstrate that diagnostically valuable information can be obtained non- intrusively, with a simple instrument not requiring ionizing radiation. The laser-based system consists of low-cost components that can be incorporated into a small device with good usability, as well as in instruments with additional sensors. The price of the research instrument was about $€ 20,000$, and exhibits large flexibility and alteration possibilities. The cost of a commercially produced instrument can be expected to be considerably lower.

The non-intrusive and harmless nature of the technique allows repeated examinations, making it possible to study the course of the disease, as well as recurring problems. The diagnostic parameters provided by the technique are the absorption of light by $\mathrm{H}_{2} \mathrm{O}$ (which is correlated to the gas volume probed), and the ratio of the absorption by $\mathrm{O}_{2}$ and $\mathrm{H}_{2} \mathrm{O}$ (which provides a measure of the oxygen concentration). As can be seen in Figure 2, the former parameter is related to the obstruction of the sinus, while the latter is related to the ventilation of the sinus. A useful way of combining the parameters in the analysis is to plot the $\mathrm{O}_{2}$ absorption vs. the $\mathrm{H}_{2} \mathrm{O}$ absorption in a scatter plot, as shown in Figure 3. Here, healthy sinuses lie close to the line $\mathrm{y}=\mathrm{x}$ above the $\mathrm{H}_{2} \mathrm{O}$ absorption threshold. Distinct deviation from the line indicates a low or high (high being physiologically unlikely) oxygen concentration. Small values close to the origin of the plot indicate low gas absorption, i.e. opacified, absent or small sinuses.

This study on the clinical applicability of the laser-based method demonstrated good sensitivity and specificity between sinuses with and without pathological findings according to the CT classification scheme. Due to the low occurrence of sinuses with pathological conditions in the study population, no statistical differentiation could be made between the CT classification subgroups, however, particular groups, such as those with opacified sinuses (Grade 2 and absent sinuses) are well distinguished with the laser-based technique. Further studies on a larger study population are needed to determine the sensitivity and specificity for specific subgroups. The large proportion of healthy sinuses in the present study population provides a good basis for threshold calculations, whereas the statistical data are not conclusive with respect to sensitivity and specificity.

Since the laser-based method provides information on the gas volume probed by the laser light, there is no intrinsic way to distinguish between small healthy sinuses and partially obstructed larger sinuses, or between an absent or a completely obstructed sinus. Using an additional method, such as acoustic techniques, together with the laser-based method could allow such distinctions to be made. Further investigations into this are required. Additional information that could be incorpora- 

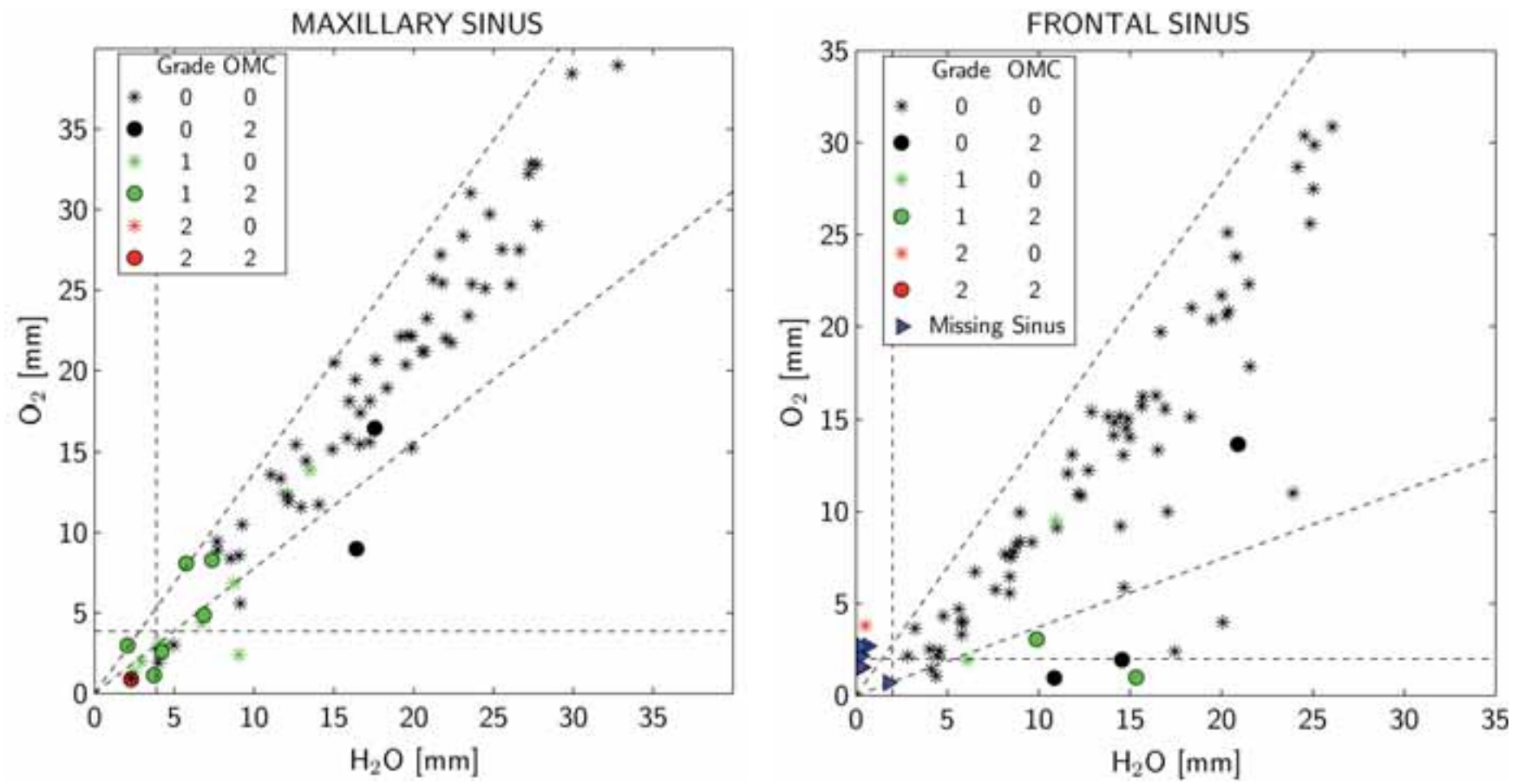

Figure 3. Absorption by $\mathrm{O}_{2}$ vs. $\mathrm{H}_{2} \mathrm{O}$ together with $95 \%$ confidence interval threshold values of $\mathrm{H}_{2} \mathrm{O}$ absorption and ratio of $\mathrm{O}_{2}$ to $\mathrm{H}_{2} \mathrm{O}$ absorption (dashed lines), for the maxillary sinuses (left) and the frontal sinuses (right).

ted into the diagnostic data is the amount of light transmission, differences between the patient's sinuses (left and right) as well as the patient's history of previous examinations.

One limitation of the laser-based technique is the penetration depth of the laser light, preventing the analysis of deep-lying sinuses, such as the ethmoidal sinuses. The sinuses located deep in the skull cannot be examined with the laser method in its present form. Theoretically, it would be possible to obtain measurements from the anterior ethmoidal cells, although we have not yet investigated this possibility. Nevertheless, in the acute clinical setting, information regarding the maxillary and frontal sinuses is more important as acute ethmoiditis is revealed by concomitant periorbital oedema.

In summary, the clinical trial presented here demonstrates the possibility of using laser light to obtain diagnostic information on the maxillary and frontal sinuses non-intrusively, without the need for ionizing radiation. The trial was carried out on 40 patients, and showed that the results obtained with this novel technique are well correlated to the classification according to the reference standard CT scan evaluation, and that the method has good sensitivity and specificity, as well as good reproducibility.

\section{Acknowledgements}

The authors gratefully acknowledge early important contributions by Linda Persson, the support of Kjell Jonsson, valuable discussions with Morgan Andersson, Lars Malm, Bo Paulsson and Karin Prellner, as well as help with data acquisition by Erik Alerstam and Zuguang Guan. The study was supported by the Swedish Research Council, a Linnaeus grant to the Lund Laser Center, the VINNOVA-financed IDRE programme, the Lund University Medical Faculty and the Acta-Oto Laryngologica Foundation.

\section{Author contributions}

$\mathrm{SS}, \mathrm{KS}, \mathrm{SL}$ and $\mathrm{ML}$ designed the trial and SS and ML developed the technique. The collection of clinical data was performed with $M L$ as the main responsible. The index test instrument including software was constructed by ML and TS. CT classification was conducted by RS. The analysis of the data obtained with the index test and the diagnostic correlations were performed by ML. The report was drafted by ML in collaboration with the other authors. All authors approved the final text.

\section{Conflict of interest statement}

$M L, K S$ and SS are shareholders in a spin-off company, GASPOROX AB. 


\section{References}

1. Thaler ED, Kennedy D (Eds.). Rhinosinusitis A guide for Diagnosis and Management, Ch 1 Abuzaid W, Thaler ER, Etiology and Impact of Rhinosinusitis. 1-15, Springer New York, 2008.

2. Anon JB, Jacobs MR, Roche R, et al. Antimicrobial treatment guidelines for acute bacterial rhinosinusitis. Otolaryng Head Neck. 2004; 130: 1-45

3. Young, J, De Sutter $A$, Merenstein D, et al. Antibiotics for adults with clinically diag nosed acute rhinosinusitis: a meta-analysis of individual patient data, Lancet. 2008 371: 908-914.

4. Lanza DC, Kennedy DW. Adult rhinosinusitis defined. Otolaryng Head Neck. 1997; $117,1-7$.

5. Benninger MS, Ferguson BJ, Hadley JA, et al. Adult chronic rhinosinusitis: definitions, diagnosis, epidemiology, and pathophysiology. Otolaryng Head Neck. 2003; 129
6. Fokkens W, Lund V, Mullol, J. European position paper on rhinosinusitis and nasal polyps 2007. A summary for otorhinolaryngologists. Rhinology. 2007: 45: 97-101.

7. Tahamiler R, Canakcioglu S, Ogreden S, et al. The accuracy of symptom-based definition of chronic rhinosinusitis, Allergy. 2007; 62: 1029-1032.

8. Anand VK, Epidemiology and economic impact of rhinosinusitis. Ann Oto Rhinol Laryn. 2004; 113: 3-5.

9. Sjöholm M, Somesfalean G, Alnis J, et al. Analysis of gas dispersed in scattering media. Opt Lett. 2001; 26: 16-18.

10. Persson L, Svanberg K, and Svanberg S. On the potential for human sinus cavity diagnostics using diode laser gas spectroscopy. Appl Phys B. 2006; 82: 313-17.

11. Persson L, Andersson M, Cassel-Engquist $\mathrm{M}$, et al. Gas monitoring in human sinuses using tunable diode laser spectroscopy. J Biomed Opt. 2007; 12: 054001.

12. Lewander M, Guan Z, Svanberg K, et al.
Clinical system for non-invasive in situ monitoring of gases in the human paranasal sinuses. Opt Express. 2009; 13: 10849 10863.

13. Lund VJ, Mackay IS. Staging in rhinosinusitis. Rhinology.1993; 31: 183-184.

14. Carenfelt C, Lundberg C. The role of local gas composition in pathogenesis of maxillary sinus emphysema. Acta Otolaryngol. 1978; 85: 116-121.

Märta Lewander

Division of Atomic Physics

Department of Physics

Lund University

Lund

Sweden

\section{ADVERTISEMENT}

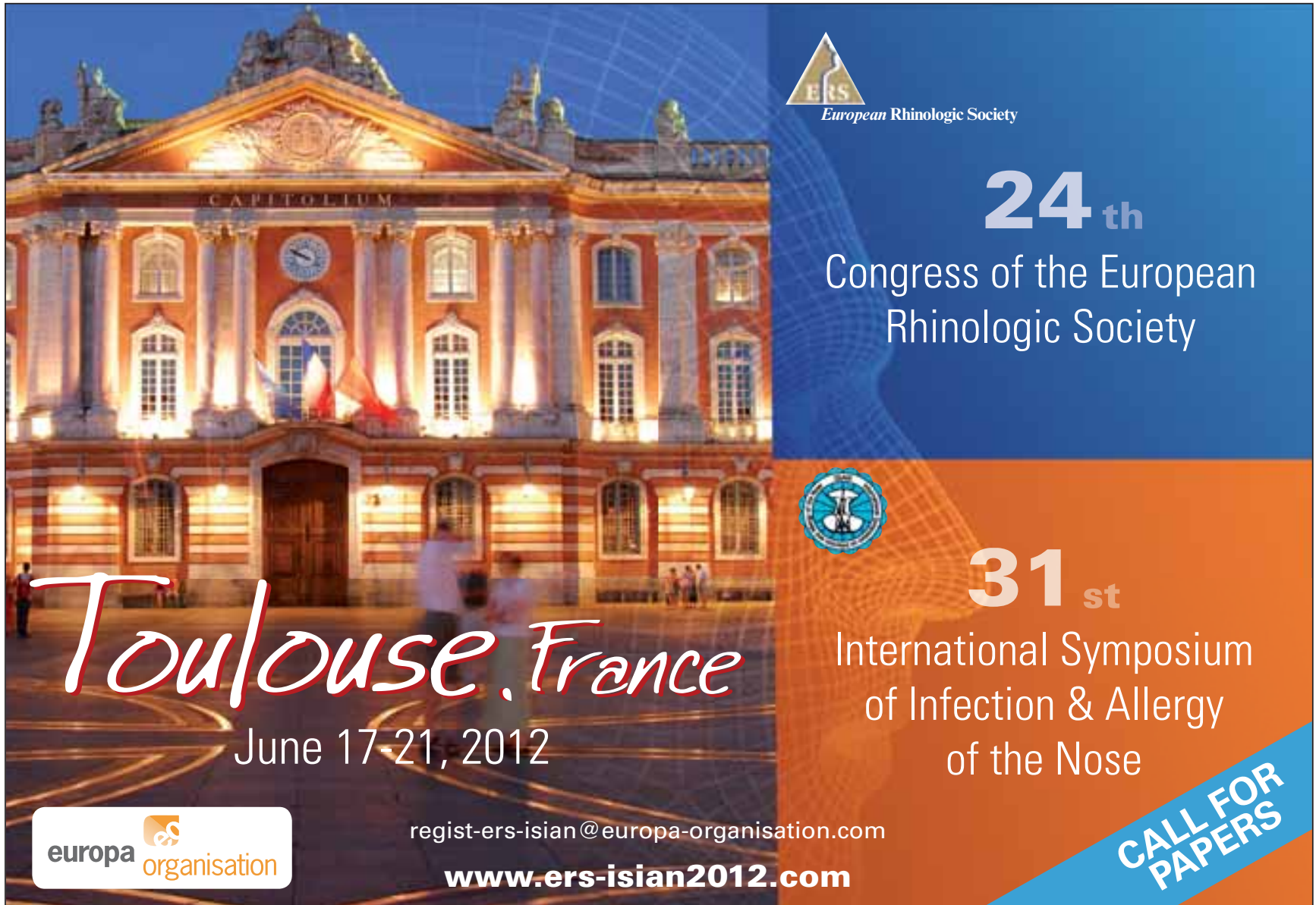

